\title{
Effect of silane coupling agent on the morphology, structure, and properties of poly(vinylidene fluoride-trifluoroethylene)/ $\mathrm{BaTiO}_{3}$ composites
}

\author{
Sara Dalle Vacche $\cdot$ Fabiane Oliveira $\cdot$ \\ Yves Leterrier • Véronique Michaud · \\ Dragan Damjanovic · Jan-Anders E. Månson
}

Received: 20 December 2013/ Accepted: 8 March 2014/Published online: 25 March 2014

(C) Springer Science+Business Media New York 2014

\begin{abstract}
Micron- and submicron-sized barium titanate $\left(\mathrm{BaTiO}_{3}\right)$ particles, untreated and surface modified with aminopropyl triethoxy silane, were incorporated in poly(vinylidene fluoride-trifluoroethylene) to fabricate composites with up to $60 \mathrm{vol} \%$ of ceramic phase. The morphology and structure of solvent cast and compressionmolded films, and their thermal, viscoelastic, and dielectric properties were investigated. When surface-modified $\mathrm{BaTiO}_{3}$ was used, it was possible to decrease both the viscoelastic and the dielectric losses of highly filled solvent cast films, while their storage modulus and relative permittivity either increased or remained equal, owing to reduced porosity and improved matrix-filler compatibility. The effect of $\mathrm{BaTiO}_{3}$ surface modification on the morphology of compression-molded films was less marked,
\end{abstract}

S. Dalle Vacche $\cdot$ F. Oliveira $\cdot$ Y. Leterrier $(\bowtie) \cdot$ V. Michaud J.-A. E. Månson

Laboratoire de Technologie des Composites et Polymères (LTC), Ecole Polytechnique Fédérale de Lausanne (EPFL), EPFL-STI-IMX-LTC, Station 12, 1015 Lausanne, Switzerland e-mail: yves.leterrier@epfl.ch

S. Dalle Vacche

e-mail: sara.dallevacche@epfl.ch

F. Oliveira

e-mail: fcobibi@gmail.com

V. Michaud

e-mail: veronique.michaud@epfl.ch

J.-A. E. Månson

e-mail: jan-anders.manson@epfl.ch

D. Damjanovic

Ceramics Laboratory (LC), Ecole Polytechnique Fédérale de

Lausanne (EPFL), EPFL-STI-IMX-LC, Station 12,

1015 Lausanne, Switzerland

e-mail: dragan.damjanovic@epfl.ch leading to unchanged viscoelastic properties, and lower permittivity and dielectric losses. For all composites the frequency dependency of the dielectric properties at low frequencies was suppressed with modified $\mathrm{BaTiO}_{3}$.

\section{Introduction}

Vinylidene fluoride (VDF) is a monomer with $\mathrm{CF}_{2}=\mathrm{CH}_{2}$ formula, which can polymerize alone or with other comonomers, some of the most commonly used being trifluoroethylene (TrFE) and hexafluoroethylene (HFP), to form VDF-based polymers. The high electronegativity of the fluorine atoms present on the polymer chains and the spontaneous alignment of the $\mathrm{C}-\mathrm{F}$ dipoles in the crystalline $\beta$-phase, in which the molecules are arranged in all-trans (TTTT) planar configuration, impart to VDF-based polymers peculiar characteristics that attracted considerable research interest in the last decades [1]. Besides being among the few existing ferroelectric polymers, VDF-based polymers show good dielectric properties, which makes them excellent candidates for the development of high energy density materials for energy storage applications. Extensive reviews on high-permittivity materials and their applications have been published recently [2, 3]. The energy density of a dielectric material is proportional to its relative permittivity, $\varepsilon$, and to the square of the applied electric field. The latter is limited by the breakdown strength, i.e., the threshold electric field above which charges start flowing through the dielectric material. The dielectric breakdown is a complex phenomenon that has been related to several mechanisms, among which the accumulation of heat due to dissipation of energy by dielectric losses [2-4]. VDF-based polymers have high electrical breakdown strength; however, their relative 
permittivity, although fairly high for a polymer, is much lower than that obtainable for ceramic materials, which on the other hand suffer from lower breakdown strengths [4]. It is therefore desirable to increase the relative permittivity of VDF-based polymers, maintaining low dielectric losses and high breakdown field. With this purpose, copolymerization of electron beam irradiated PVDF with several comonomers was successfully performed, leading to copolymers with improved dielectric properties [5-7]. Another possible route is the development of nanocomposite materials [4]; both fillers with high permittivity, as, e.g., $\mathrm{BaTiO}_{3}$ [8-13], and conducting fillers, as metal nanoparticles and graphite nanosheets, which can form percolative composites [14, 15], have been added to PVDF and its copolymers.

While most of the research on VDF-based polymer composites historically focused on their dielectric and electromechanical properties, recently more attention has also been dedicated to the understanding of their processing and their morphological, structural, thermal, and mechanical properties [16-23]. The fabrication of VDF polymer-based composites poses challenges due to the difficulty of homogeneously dispersing the inorganic filler into the fluoropolymer matrix and to the poor matrix-filler adhesion. Furthermore, in several instances fairly high volume fractions of filler (above $50 \%$ ) are needed in order to obtain the desired dielectric and electromechanical properties, and, particularly when solvent-based fabrication routes are used, porosity plays an important role [17].

As matrix-filler interfacial interactions largely determine the final structure and properties of these composites, increasing effort has been devoted to the understanding and tailoring of the matrix-filler interface $[9,20,24,25]$. The surface functionality of modified fillers was found to influence the crystalline structure of VDF polymer matrices. Clay modified with alkyl, aryl, and hydroxyl groups [26] and silica nanoparticles modified with amino and alkyl groups [27] induced the formation of different crystalline structures in P(VDF-HFP) and PVDF, respectively, depending on the type of surface functionalization. Clay modified by alkyl functionalized ionic liquids (ILs) formed intercalated structures in PVDF nanocomposites, while functionalization with fluorinated ILs led to exfoliated structures, greatly enhancing the strain at break [28]. Boron nitride nanotubes (BNNT) surface modified with dopamine allowed obtaining a higher increase of the elastic modulus and yield strength of PVDF composites with respect to pristine BNNT [29]. Surface functionalization of $\mathrm{CaCO}_{3}$ with a fluorinated alkoxysilane led to PVDF nanocomposites with enhanced filler dispersion, better thermal stability, and improved gas barrier [30], while a commercial organo-silane coated
$\mathrm{ZnO}$ only slightly increased the storage modulus of a $\mathrm{P}(\mathrm{VDF}-\mathrm{TrFE})$-based nanocomposite versus uncoated $\mathrm{ZnO}$, with no influence on the dispersion state of the filler or on the crystallinity of the matrix [31]. High permittivity nanocomposite films were fabricated by embedding, into VDF-based polymer matrices, $\mathrm{BaTiO}_{3}$ particles that were surface modified with fluorinated phosphonic acid [32], dopamine [27, 33], organofunctional titanates with long alkyl chains [34, 35], aminopropyl triethoxy silane [25], or surface hydroxylated by refluxing in aqueous $\mathrm{H}_{2} \mathrm{O}_{2}$ [36, 37]. Furthermore, in a different approach, $\mathrm{BaTiO}_{3}$ nanoparticles were generated in situ in a PVDF$g$-HEMA copolymer, in which the $-\mathrm{OH}$ group of the HEMA units acted as a bridge with the nanoparticles surface, obtaining high dielectric constant, although the dielectric losses also increased with $\mathrm{BaTiO}_{3}$ concentration [38]. Nevertheless, although the possibility to improve the dielectric properties of nanocomposites based on PVDF and its copolymers with $\mathrm{BaTiO}_{3}$ by tailoring the matrixfiller interactions has been pointed out, the effect on their thermal, functional, and mechanical properties is still largely unexplored.

In this work, the effect of the surface modification of three $\mathrm{BaTiO}_{3}$ powders with aminopropyl triethoxy silane on the thermal, viscoelastic, and dielectric properties of $\mathrm{P}(\mathrm{VDF}-\mathrm{TrFE}) / \mathrm{BaTiO}_{3}$ composites containing up to $60 \%$ volume of ceramic particles was investigated and discussed with respect to their structure and morphology.

\section{Materials and methods}

\section{Materials}

$\mathrm{P}(\mathrm{VDF}-\mathrm{TrFE})(77 / 23 \mathrm{~mol} \%)$ in powder form was provided by Solvay Solexis $\mathrm{SpA}$ (Bollate, MI, Italy). Three $\mathrm{BaTiO}_{3}$ powders were used as piezoelectric ceramic fillers. The first powder (BT1) was barium titanate (IV), $<2 \mu \mathrm{m}, 99.9 \%$ from Sigma-Aldrich (St. Louis, MO, USA), with a declared average particle size of $1.1 \mu \mathrm{m}$. The second one (BT2) was an in-house made $\mathrm{BaTiO}_{3}$ powder $(0.7 \mu \mathrm{m})$, obtained by milling $\mathrm{BaCO}_{3}$ and $\mathrm{TiO}_{2}$ powders in stoichiometric ratio, and performing calcination at $1100{ }^{\circ} \mathrm{C}$ for $3 \mathrm{~h}$ followed by further milling. The characterization of the BT1 and BT2 powders was reported in detail previously [17]. The third powder (BT3) was $\mathrm{BaTiO}_{3} 99.95 \%$, electronic grade, average particle size $0.2 \mu \mathrm{m}$ from Inframat Advanced Materials LLC (Manchester, CT, USA). The silane coupling agent was (3-aminopropyl)triethoxysilane (APTES), $99 \%$, supplied by Sigma-Aldrich (St. Louis, MO, USA). Methyl ethyl ketone (MEK, 2-butanone, 99+ \%) was supplied by Acros Organics (Geel, Belgium) and ethanol, $94 \%$ by Reactolab SA (Servion, Switzerland). 
Surface modification of $\mathrm{BaTiO}_{3}$

The BT1 powder was surface modified with $0.5,1.0$, and $2.0 \mathrm{wt} \%$ APTES in ethanol/water $(95 / 5 \mathrm{vol} \%)$. The ethanol/water solutions containing $\mathrm{BaTiO}_{3}$ and APTES were first sonicated with an ultrasonic horn (Digital Sonifier 450, Branson Ultrasonics Corporation, Danbury, CT, USA) for $5 \mathrm{~min}$, then stirred with a magnetic stirrer at $70{ }^{\circ} \mathrm{C}$ for $1 \mathrm{~h}$. The $\mathrm{BaTiO}_{3}$ powder was then separated by centrifugation on a CR412 centrifuge (Jouan S.A.S., St. Herblain, France) at $4700 \mathrm{rpm}$ for $10 \mathrm{~min}$ and dried at $110^{\circ} \mathrm{C}$ for $1 \mathrm{~h}$ to allow for silanol condensation. Washing with ethanol and centrifugation were repeated twice, and finally, the powders were dried at $80{ }^{\circ} \mathrm{C}$ in vacuum overnight. The BT2 and BT3 powders were surface modified with $1 \mathrm{wt} \%$ APTES following the same procedure.

\section{Preparation of the films}

Solvent cast films were obtained as follows. The polymer powder was dissolved in MEK at $60{ }^{\circ} \mathrm{C}$. For the composites containing 30, 45, and $60 \%$ in volume of $\mathrm{BaTiO}_{3}$ appropriate quantities of the powders, calculated taking the density of the $\mathrm{BaTiO}_{3}$ equal to $6.0 \mathrm{~g} \mathrm{~cm}^{-3}$ according to the suppliers' information, and that of $\mathrm{P}(\mathrm{VDF}-\mathrm{TrFE})$ equal to $1.9 \mathrm{~g} \mathrm{~cm}^{-3}$ [39], were slowly added to the P(VDF-TrFE)/ MEK solution while stirring. The solids (polymer + ceramics) to solvent weight ratio was 1:10 for all compositions. The mixtures were then further stirred with a magnetic stirrer for $1 \mathrm{~h}$ at $60{ }^{\circ} \mathrm{C}$. Sonication with the Digital Sonifier 450 ultrasound horn for 5 min with $50 \mathrm{~s}$ on/off pulses followed, then the mixtures were homogenized with a mechanical disintegrator (IKAWERK Ultraturrax T25) at $5600 \mathrm{rpm}$ during $20 \mathrm{~min}$, and finally left in vacuum for $10 \mathrm{~min}$ in order to remove the entrapped air before casting on glass. The solvent was evaporated in a vacuum oven, increasing the temperature to $80^{\circ} \mathrm{C}$ over $5 \mathrm{~min}$ and allowing the film to dry at these conditions for $4 \mathrm{~h}$. The films were then annealed at $135^{\circ} \mathrm{C}$ for $15 \mathrm{~min}$ to increase crystallinity. The films obtained were $80-130 \mu \mathrm{m}$ thick.

Compression-molded films of PVDF-TrFE and of the composites were obtained by superposing two layers of solvent cast films and hot pressing them in a TP50 hydraulic press (Fontijne Holland, Netherlands) with a pressure of $5 \mathrm{MPa}$, heating from 25 to $200{ }^{\circ} \mathrm{C}$ in $20 \mathrm{~min}$, holding at $200{ }^{\circ} \mathrm{C}$ for $10 \mathrm{~min}$, and cooling to $25^{\circ} \mathrm{C}$ in $20 \mathrm{~min}$. The composites containing up to $45 \mathrm{vol} \%$ of ceramics were prepared inside a thin aluminum mold, obtaining thicknesses of $60-120 \mu \mathrm{m}$. As this set-up proved unsuitable for the composites containing $60 \mathrm{vol} \%$ particles, they were therefore prepared in a larger steel mold, obtaining 130-180 $\mu \mathrm{m}$ thick films. The steel mold had a higher thermal inertia, therefore the temperature control was somewhat less precise than with the aluminum set-up.

Composites were prepared containing 30, 45, and 60 vol $\%$ of the unmodified and modified BT1 powders, and 60 vol\% of the unmodified and modified BT2 and BT3 powders. In what follows solvent cast films are indicated with the code $\mathrm{SCx}-\mathrm{y}-\mathrm{z}$ and compression-molded films with the code $\mathrm{CMx}-\mathrm{y}-\mathrm{z}$, where $x$ is equal to 1,2 , or 3 for materials containing BT1, BT2, or BT3 particles, respectively, $y$ indicates the amount of $\mathrm{BaTiO}_{3}$ in volume percent, and $z$ the amount of APTES (in weight percent) used for the powder modification.

\section{Characterization techniques}

The surface modification of the powders was verified by means of thermogravimetric analysis (TGA) with a TGA/ SDTA 851e apparatus (Mettler Toledo, Switzerland), heating from 30 to $800{ }^{\circ} \mathrm{C}$ at $10 \mathrm{~K} \mathrm{~min}^{-1}$ under a $30 \mathrm{ml} \mathrm{m^{-1 }} \mathrm{N}_{2}$ flow in alumina crucibles.

The morphology of the nanocomposites was observed in a Philips XL30 FEG (Philips, The Netherlands) scanning electron microscope (SEM). The samples were prepared by cryo-fracture and carbon coated to prevent charging.

The density of the nanocomposite films was measured on an AT261 DeltaRange balance equipped with a density determination kit ME-210250 (Mettler Toledo, Switzerland), by weighing the samples in air and water. The porosity of the composites was estimated by comparing the measured density to the expected one calculated on the basis of the weight fractions and densities of the matrix and filler. Due to the weighing error induced by the thin film shape of the samples when immersed in water and to the uncertainties on the real densities of the $\mathrm{BaTiO}_{3}$ particles, the porosity values obtained by this method cannot be considered absolute values; however, they are suitable for comparing porosity of films made with the same $\mathrm{BaTiO}_{3}$ powder, pristine, and surface modified.

$\mathrm{X}$-ray diffraction was performed on the films using $\mathrm{CuK} \alpha$ radiation on a D8 DISCOVER diffractometer (Bruker AXS, USA) to assess the crystalline structure of $\mathrm{BaTiO}_{3}$ in the composites. The scans were run with a $0.02^{\circ}$ increment and at $1^{\circ} \min ^{-1}$ speed.

The crystallinity and thermal transitions of $\mathrm{P}(\mathrm{VDF}-$ TrFE) in the films were studied by means of differential scanning calorimeter (DSC Q100, TA Instruments, USA). The measurements were carried out between -80 and $200{ }^{\circ} \mathrm{C}$ at a heating rate of $10 \mathrm{~K} \mathrm{~min}^{-1}$ under $\mathrm{N}_{2}$ flow.

Dynamic mechanical analysis (Q800 DMA, TA Instruments, USA) was performed on the films in tensile configuration with an excitation frequency of $1 \mathrm{~Hz}$. An applied strain of $0.05 \%$ was chosen in order to stay within the linear viscoelastic region, which was smaller for the composites 
than for the pure polymer. The temperature was raised from -50 to $150{ }^{\circ} \mathrm{C}$ at a heating rate of $3 \mathrm{~K} \mathrm{~min}^{-1}$.

Gold electrodes were sputtered on the SC and $\mathrm{CM}$ samples containing $60 \mathrm{wt} \% \mathrm{BaTiO}_{3}$ in order to enable their dielectric characterization. Capacitance and losses were measured as a function of frequency with an impedance/ gain-phase analyzer HP4194A (Hewlett Packard, USA) at room temperature between $100 \mathrm{~Hz}$ and $1 \mathrm{MHz}$ and with a voltage of $1 V_{\text {rms }}$. Relative permittivity was then calculated from capacitance, knowing the area and thickness of each sample.

\section{Results}

Powder surface modification analysis

Figure 1 shows the evolution of the weight of the untreated and surface-modified $\mathrm{BaTiO}_{3}$ powders with increasing temperature. The unmodified powders show an initial weight decrease up to $200{ }^{\circ} \mathrm{C}$ that is attributed to loss of surface adsorbed water, then a plateau until about $500{ }^{\circ} \mathrm{C}$, when the loss of surface hydroxyl groups occurs. The surface-modified powders show a less steep initial weight loss before $200{ }^{\circ} \mathrm{C}$, indicating that less water is adsorbed due to the presence of hydrophobic groups on their surface. At about $300{ }^{\circ} \mathrm{C}$ a weight loss due to the decomposition of the hydrocarbon tails of the silanes occurs. One can notice that for all BT1-modified powders the weight loss attributable to the silane is of about $0.2 \%$, showing that increasing the silane $/ \mathrm{BaTiO}_{3}$ ratio during the modification procedure did not lead to a significant increase of the amount of silane on the surface of the particles.

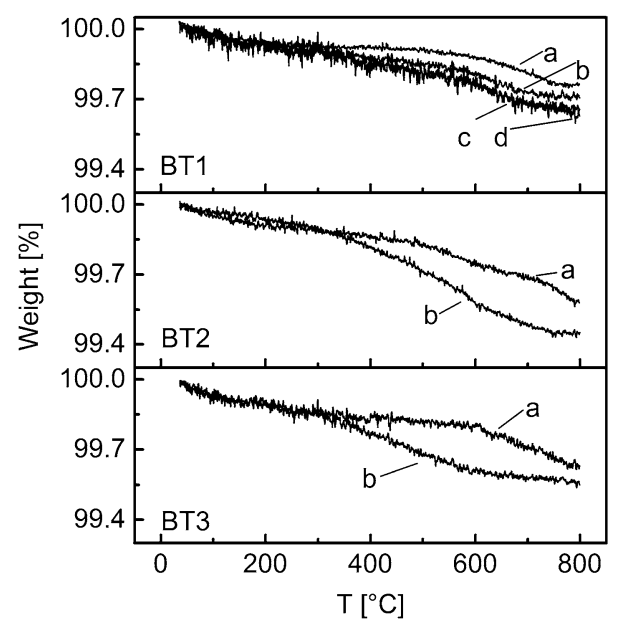

Fig. 1 TGA of $\mathrm{BaTiO}_{3}$ particles: BT1 unmodified $(a)$ and modified with $0.5 \%(b), 1 \%(c)$ and $2 \%(d)$ APTES; BT2 unmodified $(a)$ and modified with $1 \%$ APTES $(b)$; BT3 unmodified $(a)$ and modified with $1 \%$ APTES $(b)$
Morphology and structure of the composites

The SEM observation of cryo-fractured surfaces of the solvent cast and compression-molded composites showed a homogeneous through thickness distribution of the $\mathrm{BaTiO}_{3}$ particles in all materials. Figures 2 and 3 show the micrographs obtained for the composites containing 60 vol\% of BT1, BT2, and BT3 untreated (a, c, e), and modified with $1 \mathrm{wt} \%$ APTES (b, d, f). For the composites made with BT1 and BT3, when surface-modified powders were used, the occurrence of large particles aggregates was reduced. For the composites made with BT2, as the untreated powder was already well dispersed, the improvement obtained with powder modification was less marked. Generally for the composites made with unmodified $\mathrm{BaTiO}_{3}$, the surface of the bare particles was exposed after fracture, while for the composites made with surface-modified powders the particles remained covered by a layer of polymer, as shown in the insets of Fig. 3e, f, indicating a better matrix-filler compatibility and adhesion. For the solvent cast composites made with BT1 and BT3 powders one can observe that the presence of large pores was reduced upon surface modification of the $\mathrm{BaTiO}_{3}$ particles. This is in agreement with the porosity values calculated from density measurements for the solvent cast materials containing $60 \mathrm{vol} \% \mathrm{BaTiO}_{3}$ : about $28 \%$ porosity for the materials made with untreated BT1 and BT3 particles, and $14-20 \%$ porosity for the other solvent cast materials. On the other hand, as the compression-molding step reduces the porosity, this difference was largely suppressed for the resulting CM composites. The porosities calculated from density measurements were lower than $10 \%$ for all compressionmolded films containing $60 \mathrm{vol} \% \mathrm{BaTiO}_{3}$, with no significant differences between the different materials. In lower magnification images of CM1-60-0 and CM1-60-1 (insets of Fig. 3a, b), the interface between the two films superposed to make the $\mathrm{CM}$ materials was visible, while it was not for the composites made with BT2 and BT3. This might be due to differences in the rheology of the molten composites, which would need to be investigated further.

The XRD patterns of CM composites with $60 \mathrm{vol} \%$ of particles are shown in Fig. 4, and are representative also of the $\mathrm{SC}$ composites. The tetragonal form of $\mathrm{BaTiO}_{3}$ crystal structure can be identified by the double peak corresponding to the reflections of the (200) and (002) planes, indicated by arrows in the figure. No difference in the tetragonal structure of the $\mathrm{BaTiO}_{3}$ particles embedded in the polymer matrix due to the surface modification was detected both for solvent cast and compression-molded films. 

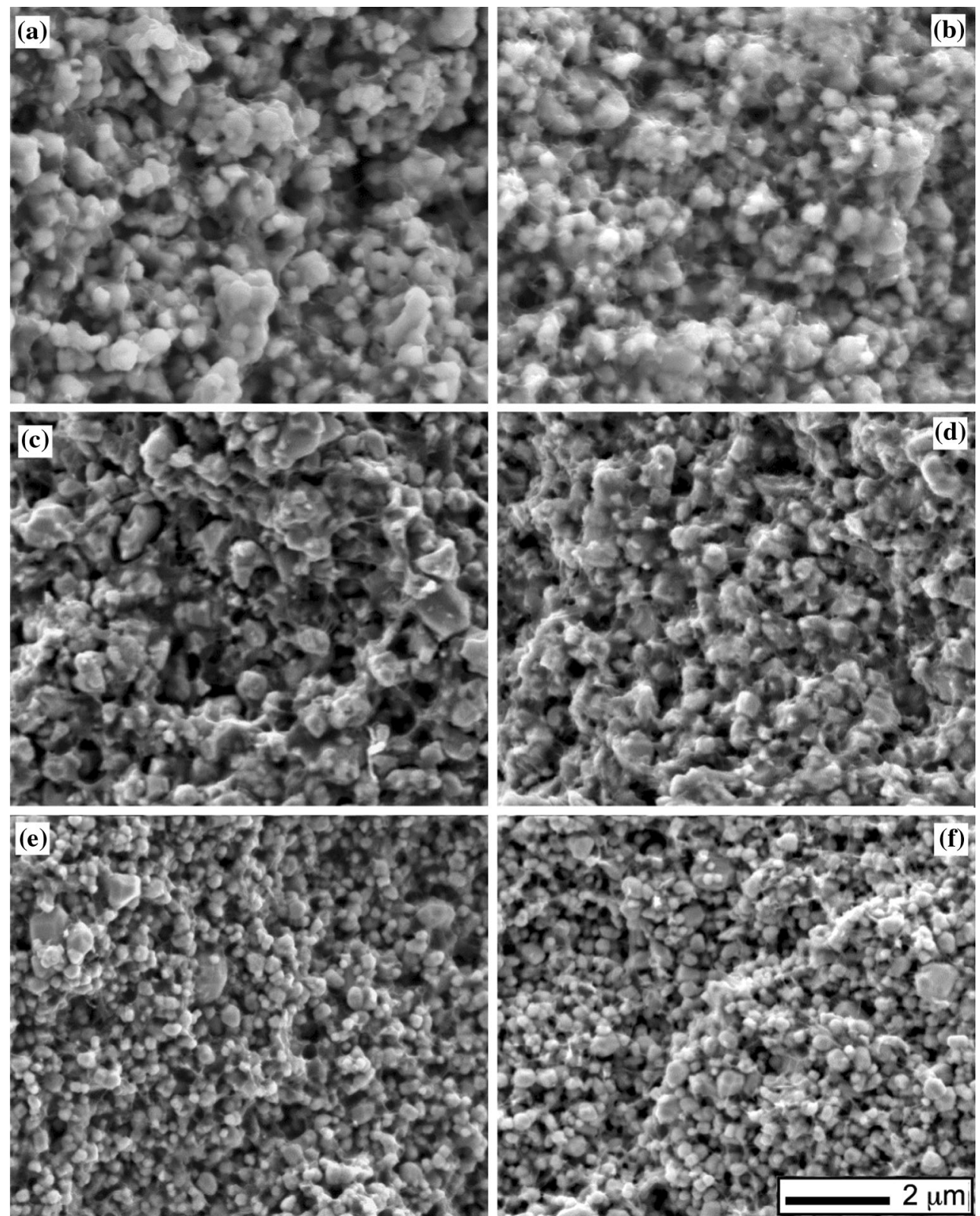

Fig. 2 SEM micrographs of a SC1-60-0, b SC1-60-1, c SC2-60-0, d SC2-60-1, e SC3-60-0, and f SC3-60-1

Thermal transitions and crystallinity of the polymer matrix

The thermograms of SC and CM composites made with unmodified and modified $\mathrm{BaTiO}_{3}$ particles, are shown in Figs. 5 and 6. The thermograms of the composites made with BT1 modified with $1 \%$ silane are representative also of those of the composites made with BT1 modified with 0.5 and $2 \%$ silane. All DSC thermograms showed the two endotherm peaks corresponding to the ferroelectric to paraelectric phase transition (Curie transition) of $\mathrm{P}(\mathrm{VDF}-$ TrFE), at the lower temperature, and to the melting of the crystallites of $\mathrm{P}(\mathrm{VDF}-\mathrm{TrFE})$, at the higher temperature. It has to be noticed that the $\mathrm{BaTiO}_{3}$ has a Curie transition at a similar temperature to that of the $\mathrm{P}(\mathrm{VDF}-\mathrm{TrFE})$; however, due to the much lower intensity, the corresponding peak was not detectable. The Curie temperatures $\left(T_{\mathrm{C}}\right)$ and melting temperatures $\left(T_{\mathrm{m}}\right)$ of all tested materials are summarized in Table 1. The structural differences between SC and $\mathrm{CM}$ composites arising from the different fabrication processes, which are reflected in the DSC thermograms, were discussed in detail in a previous paper [17] and will not be specifically covered here.

For all composites, upon addition of $\mathrm{BaTiO}_{3}$ particles, only the intensity of the endotherm peaks was reduced with increasing ceramic volume fraction, but their shape and 
Fig. 3 SEM micrographs of a CM1-60-0, b CM1-60-1, c CM2-60-0, d CM2-60-1, e CM3-60-0, and f CM3-60-1
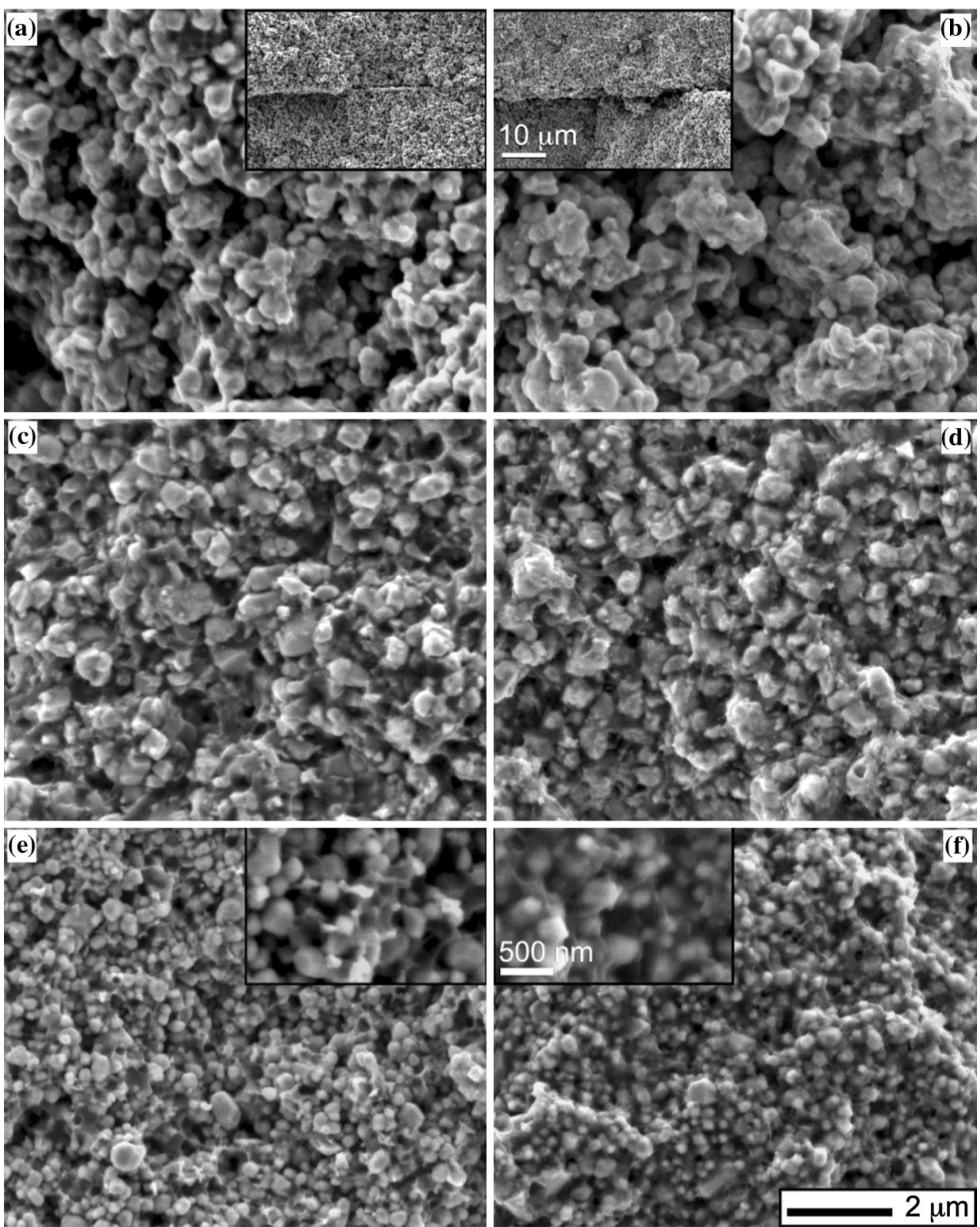

position did not change. No significant differences could be detected between the thermograms of the composites made with unmodified and modified powders over the whole range of compositions. Only the CM composites containing $60 \mathrm{vol} \% \mathrm{BaTiO}_{3}$, showed some variability in the shape and position of the endotherm peaks, however with no correlation with the $\mathrm{BaTiO}_{3}$ surface modification. The broadening of the Curie transition peak and the appearance of a shoulder at the lower temperature side of the transition is consistent with the formation of a less-ordered ferroelectric phase, as described for $\mathrm{P}(\mathrm{VDF}-\mathrm{TrFE})$ crystallized above $T_{\mathrm{C}}$ [40]. This variability is thought to be mainly due to small temperature variations in the steel mold, as indeed the $\mathrm{P}(\mathrm{VDF}-\mathrm{TrFE})$ polymer crystalline structure is very sensitive to even small variations in the processing conditions.

The effect of the addition of unmodified and modified $\mathrm{BaTiO}_{3}$ particles on the degree of crystallinity of the polymer matrix was assessed by calculating for each composite the enthalpy of fusion normalized to the mass fraction of the polymer, $\Delta H_{\mathrm{f}}$ (reported in Table 1), as follows:

$\Delta H_{\mathrm{f}}=\frac{\Delta \mathrm{H}_{\mathrm{f}}^{\exp }}{x_{\mathrm{w}}^{\mathrm{p}}}$,

where for each composite, $\Delta H_{\mathrm{f}}^{\mathrm{exp}}$ is the measured enthalpy of fusion, and $x_{\mathrm{w}}^{\mathrm{p}}$ is the mass fraction of the polymer. Although there is a certain scattering of the $\Delta H_{\mathrm{f}}$ data, a 


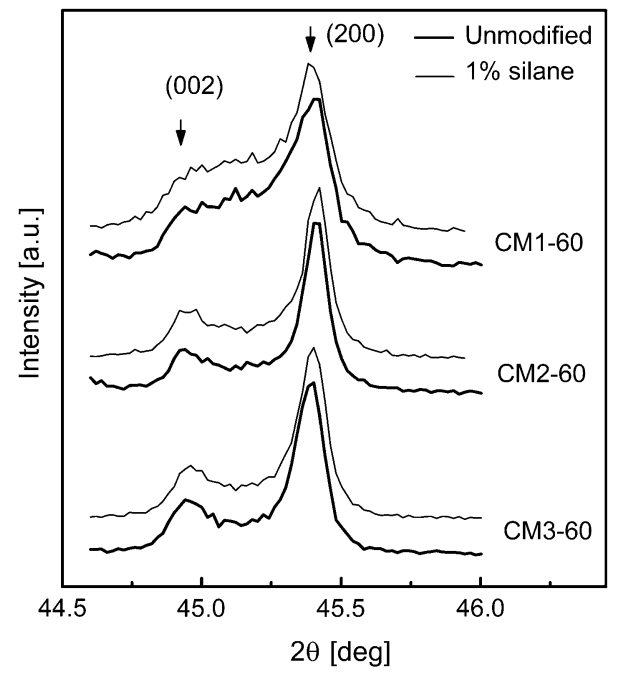

Fig. 4 XRD patterns of composite CM films with 60 vol\% $\mathrm{BaTiO}_{3}$, unmodified and modified with $1 \%$ silane

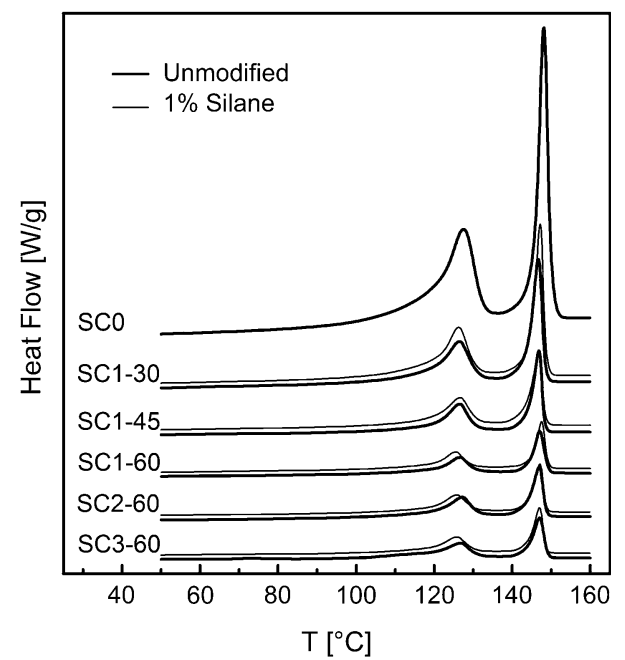

Fig. 5 DSC thermograms of solvent cast films of $\mathrm{P}(\mathrm{VDF}-\mathrm{TrFE})$ and composites made with unmodified $\mathrm{BaTiO}_{3}$ and with $\mathrm{BaTiO}_{3}$ modified with $1 \%$ silane

slight decrease in crystallinity at the high ceramic volume fractions can be noticed both for the SC and the CM composites. However, at each powder volume fraction, no significant differences related to the surface modification of the $\mathrm{BaTiO}_{3}$ particles could be detected.

\section{Viscoelastic properties}

Figures 7 and 8 show the temperature dependence of the storage modulus $\left(E^{\prime}\right)$ and of the damping factor $(\tan \delta)$ of $\mathrm{P}(\mathrm{VDF}-\mathrm{TrFE})$ and composite films fabricated using untreated and surface-modified powders. In order to better visualize the trends of the storage moduli with $\mathrm{BaTiO}_{3}$ concentration and surface modification, in Fig. 9a are

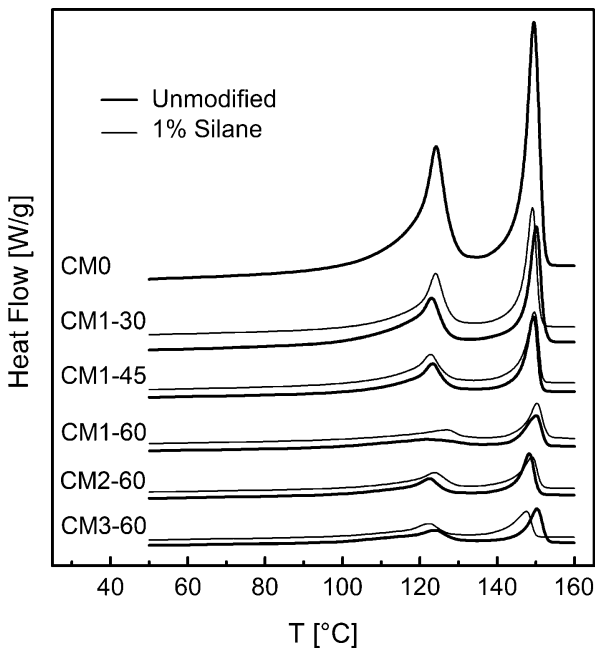

Fig. 6 DSC thermograms of compression-molded films of $\mathrm{P}(\mathrm{VDF}-$ TrFE) and composites made with unmodified $\mathrm{BaTiO}_{3}$ and $\mathrm{BaTiO}_{3}$ modified with $1 \%$ silane

shown the values of $E^{\prime}$ measured at $25{ }^{\circ} \mathrm{C}$, and their theoretical lower and upper bounds calculated with the Hashin-Shtrikman (H-S) model [41]. The calculation of the $\mathrm{H}-\mathrm{S}$ bounds was reported in detail elsewhere [17]. For BT1, the results shown for the composites made with particles modified with $1 \%$ APTES are representative of all materials made with BT1 surface-treated particles.

For the solvent cast materials, the storage modulus decreased with temperature, and two steep drops of $E^{\prime}$ were observed corresponding to the phase transitions of $\mathrm{P}(\mathrm{VDF}-$ TrFE), i.e., the ferroelectric to the paraelectric phase transition at about $110{ }^{\circ} \mathrm{C}$ and the onset of melting above $130{ }^{\circ} \mathrm{C}$. For all the composites containing $30 \mathrm{vol} \% \mathrm{BT} 1$, untreated, and modified, the modulus was more than double with respect to the one of the pure polymer. With BT1 unmodified particles no further increase was obtained at 45 vol\% and then $E^{\prime}$ decreased markedly at $60 \mathrm{vol} \%$, falling well below the $\mathrm{H}-\mathrm{S}$ lower bound. When surface-modified BT1 particles were used, at 45 vol $\% E^{\prime}$ slightly increased, having a value about $20 \%$ higher than that of SC1-45-0, and with $60 \mathrm{vol} \% E^{\prime}$ decreased somewhat, to a value higher by about $60 \%$ than with unmodified BT1, just slightly below the $\mathrm{H}-\mathrm{S}$ lower bound. A similar behavior was observed with BT3, for which the composite containing modified particles showed a $100 \%$ increase in modulus with respect to the one containing pristine particles. The SC2-60-0 composite showed the highest $E^{\prime}$ values among the composites made with untreated $\mathrm{BaTiO}_{3}$, particularly above room temperature, consistently with the better dispersion of BT2 in the matrix. The modulus of SC2-60-1 was similar to that of SC2-60-0 until about $50{ }^{\circ} \mathrm{C}$, and then it decreased somewhat more rapidly with temperature until melting of the polymer matrix. It must be also noted that in 
Table 1 Curie temperature $\left(T_{\mathrm{C}}\right)$, melting temperature $\left(T_{\mathrm{m}}\right)$, and heat of fusion $\left(\Delta H_{\mathrm{f}}\right)$ of the SC and CM materials (the standard deviation has been indicated in parenthesis for the unfilled polymers)

\begin{tabular}{|c|c|c|c|}
\hline & $T_{\mathrm{C}}\left({ }^{\circ} \mathrm{C}\right)$ & $T_{\mathrm{m}}\left({ }^{\circ} \mathrm{C}\right)$ & $\Delta H_{\mathrm{f}}(\mathrm{J} / \mathrm{g})$ \\
\hline $\mathrm{SCO}$ & $127.2(0.5)$ & $147.1(1.4)$ & $30.0(1.5)$ \\
\hline SC1-30-0 & 126.5 & 146.7 & 31.7 \\
\hline SC1-30-0.5 & 127.4 & 146.7 & 27.1 \\
\hline SC1-30-1 & 126.1 & 147.2 & 35.6 \\
\hline SC1-30-2 & 126.5 & 147.2 & 33.1 \\
\hline SC1-45-0 & 126.6 & 146.8 & 29.4 \\
\hline SC1-45-1 & 126.7 & 146.8 & 30.5 \\
\hline SC1-60-0 & 126.6 & 147.1 & 26.4 \\
\hline SC1-60-0.5 & 126.2 & 147.0 & 28.6 \\
\hline SC1-60-1 & 125.4 & 147.5 & 25.8 \\
\hline SC1-60-2 & 126.0 & 147.2 & 27.6 \\
\hline SC2-60-0 & 127.2 & 146.9 & 33.1 \\
\hline SC2-60-1 & 127.1 & 147.0 & 28.6 \\
\hline SC3-60-0 & 126.8 & 147.0 & 26.7 \\
\hline SC3-60-1 & 125.8 & 146.9 & 27.2 \\
\hline CM0 & $124.7(0.5)$ & $148.3(1.0)$ & $27.3(0.5)$ \\
\hline CM1-30-0 & 123.1 & 150.1 & 30.3 \\
\hline CM1-30-0.5 & 124.1 & 148.9 & 26.3 \\
\hline CM1-30-1 & 124.1 & 149.1 & 28.6 \\
\hline CM1-30-2 & 122.9 & 149.8 & 31.5 \\
\hline CM1-45-0 & 123.3 & 149.4 & 28.3 \\
\hline CM1-45-0.5 & 123.2 & 149.5 & 26.8 \\
\hline CM1-45-1 & 122.8 & 149.6 & 29.2 \\
\hline CM1-45-2 & 123.2 & 149.4 & 35.8 \\
\hline CM1-60-0 & 121.4 & 150.0 & 24.2 \\
\hline CM1-60-0.5 & 124.4 & 149.3 & 25.2 \\
\hline CM1-60-1 & 126.8 & 150.3 & 26.8 \\
\hline CM1-60-2 & 123.5 & 148.5 & 24.4 \\
\hline CM2-60-0 & 122.5 & 148.2 & 28.5 \\
\hline CM2-60-1 & 123.5 & 148.6 & 26.7 \\
\hline CM3-60-0 & 124.1 & 150.1 & 24.9 \\
\hline CM3-60-1 & 122.4 & 147.6 & 21.8 \\
\hline
\end{tabular}

several DMA tests the SC composites made with 45 and 60 vol\% of untreated $\mathrm{BaTiO}_{3}$ powders already failed at about $110{ }^{\circ} \mathrm{C}$ under the small strain applied, while this did not happen for the materials made with modified powders. During the preparation of the samples it was also qualitatively observed that they were more fragile and easily broken while handling in comparison with their homologues made with modified powders. In order to evaluate whether the low modulus for the SC materials made with $60 \mathrm{vol} \%$ untreated BT1 and BT3 could be attributed to their higher porosity, the $\mathrm{H}-\mathrm{S}$ bounds were recalculated by taking into account the porosity of the composites. The porosity was considered concentrated in the matrix, and the modulus of the porous matrix was calculated as that of a closed cell foam, for which:

$\frac{E_{\mathrm{f}}}{E_{\mathrm{p}}}=0.32\left[\left(1-\phi_{\mathrm{v}}\right)^{2}+\left(1-\phi_{\mathrm{v}}\right)\right]$,

where $E_{\mathrm{f}}$ and $E_{\mathrm{p}}$ are the moduli of the foam and of the polymer, respectively, and $\phi_{\mathrm{v}}$ is the volume fraction of the pores [42]. The values of $E^{\prime}$ at $25^{\circ} \mathrm{C}$ obtained introducing the calculated moduli for the porous matrices into the $\mathrm{H}-\mathrm{S}$ bounds equations are reported in Fig. $9 \mathrm{~b}$ together with the experimental values. As it can be observed, the calculated $\mathrm{H}-\mathrm{S}$ bounds and the experimental data follow similar trends.

The storage modulus of the compression-molded films showed two small inflections corresponding to the $\beta$-relaxation and $\alpha$-relaxation, and two steep drops corresponding to the Curie transition and melting. The storage modulus increased with increasing $\mathrm{BaTiO}_{3}$ content, following a similar trend as the $\mathrm{H}-\mathrm{S}$ lower bound. No significant differences between the composites made with untreated BT1 and their counterparts made with functionalized BT1 were detected. Only the CM1-60-1 composite failed around $110{ }^{\circ} \mathrm{C}$ under the small strain applied; however, the reason for this is not fully understood as no other compression-molded samples made with modified powder failed before the melting point of the matrix. On the other hand, the compression-molded composites containing unmodified BT2 and BT3 were too fragile, and it was not possible to obtain proper samples to be tested by DMA. When modified BT2 and BT3 powders were used, DMA tests could be performed and their storage moduli were similar to that obtained with modified BT1 powder.

For the solvent cast films, the $\tan \delta$ values were generally higher for the composites than for the pure polymer, and the composites made with untreated ceramic particles had higher $\tan \delta$ values than their homologues made with treated particles. For the compression-molded materials the $\tan \delta$ values of the composites, both with unmodified and silane-treated particles, were similar or lower than those of the polymer, as it would be expected. Generally, the $\tan \delta$ curves of $\mathrm{P}(\mathrm{VDF}-\mathrm{TrFE})$ show three transitions in the temperature range explored, before the melting point. At the lower temperature, the $\beta$-relaxation peak is usually attributed to segmental motions in the amorphous phase (glass transition) [43-45], although recently some authors proposed a contribution by domain walls and defects in crystalline phase [46, 47]. In the region between 0 and $100{ }^{\circ} \mathrm{C}$, a second relaxation process appears, indicated as $\alpha$-relaxation, the nature of which has not been fully clarified yet [48-50]. Finally, a peak just before the steep increase due to the melting corresponds to the Curie transition of $\mathrm{P}(\mathrm{VDF}-\mathrm{TrFE})$. The $\beta$-relaxation peak was well defined in the $\tan \delta$ curves of all SC and CM materials, and 
Fig. 7 Storage modulus and $\tan \delta$ of solvent cast composites made with unmodified $\mathrm{BaTiO}_{3}$ and $\mathrm{BaTiO}_{3}$ modified with $1 \%$ silane

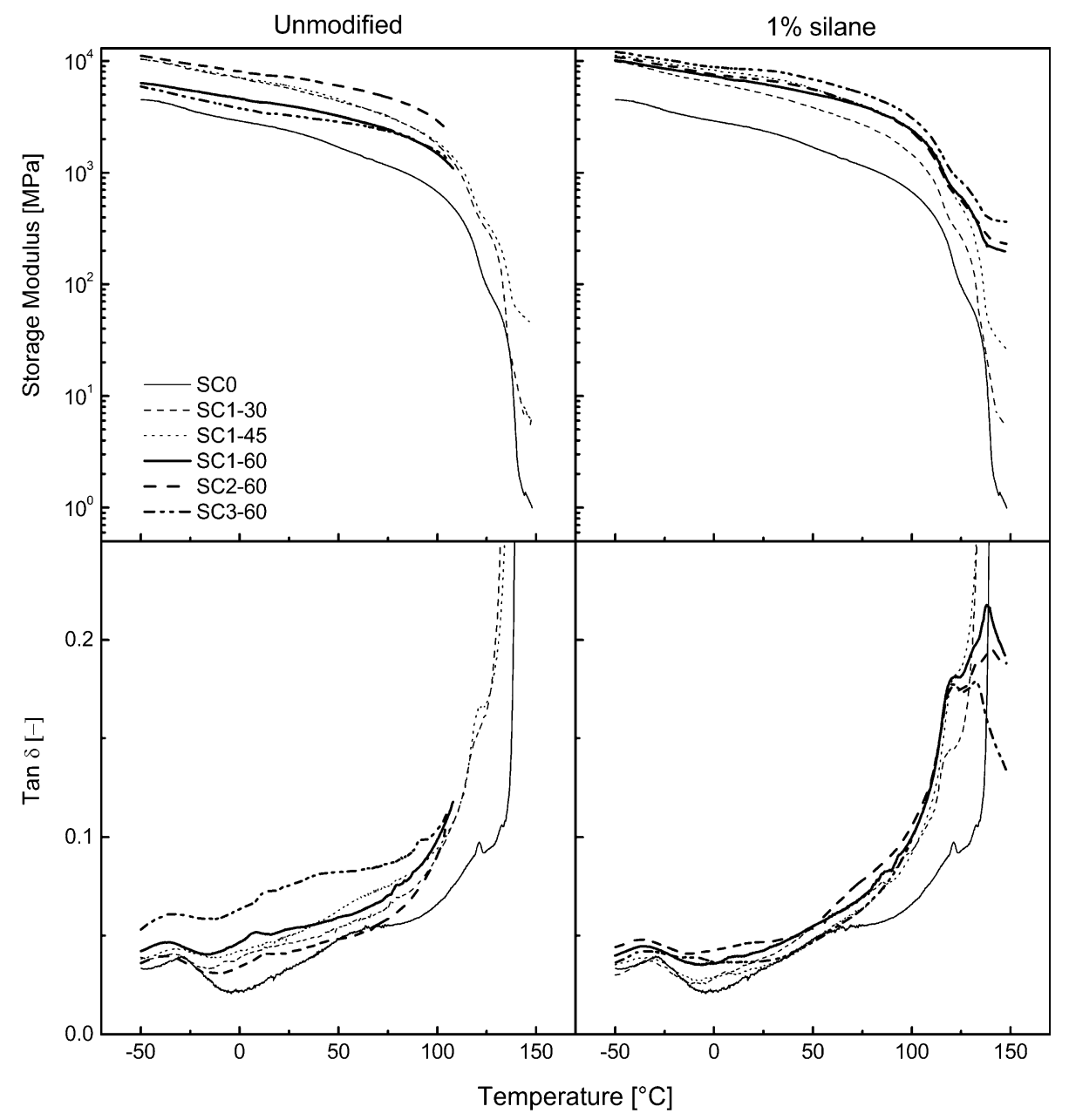

its intensity decreased with decreasing polymer volume fraction. The peak maximum shifted at lower temperatures with increasing volume fractions of $\mathrm{BaTiO}_{3}$. The $\alpha$-relaxation, that appeared for $\mathrm{SC} 0$ as a broad and not welldefined peak around $50{ }^{\circ} \mathrm{C}$, and for $\mathrm{CM} 0$ as a betterdefined peak at about $20^{\circ} \mathrm{C}$, either had lower intensity and shifted to lower temperatures or completely disappeared in the composites. Given the uncertainty on the nature of this peak, it is difficult to make hypotheses about the reasons for this shift. No trends, however, appeared for both the $\beta$ - and $\alpha$-relaxations when comparing unmodified and modified powders.

\section{Dielectric properties}

The relative permittivity and the dielectric loss tangent $\left(\tan \delta_{\text {diel }}\right)$ of all the solvent cast and compression-molded composites filled with $60 \mathrm{vol} \% \mathrm{BaTiO}_{3}$ are shown as a function of frequency in Figs. 10 and 11. For all solvent cast and compression-molded composites made with untreated BT1, BT2, and BT3 powders, the relative permittivity showed a steeper decrease with frequency in the
$10^{2}-10^{4} \mathrm{~Hz}$ range than for the composites made with modified powders. A similar effect appeared also for dopamine-treated $\mathrm{PVDF} / \mathrm{BaTiO}_{3}$ composites [33]. For BT1 and BT2 solvent cast composites, the surface modification of the powder led to an increase of the permittivity of the order of 10-20\%, from about 65 and 70 at $10^{4} \mathrm{~Hz}$, for composites made with unmodified BT1 and BT2, respectively, to about 85 at $10^{4} \mathrm{~Hz}$ for the modified powders, while for BT3 no difference was detected above $10^{4} \mathrm{~Hz}$, with values close to 80 both for untreated and silylated powder. For the compression-molded materials, the composites made with untreated powders showed higher permittivity than the ones made with surface-modified powders. Particularly, the permittivity of CM3-60-0 started at a very high value, above 300 at $10^{2} \mathrm{~Hz}$, and then decreased steeply to about 120 for frequencies above $10^{5} \mathrm{~Hz}$. This result is in line with that obtained by Dang et al. [51] for $\mathrm{PVDF} / \mathrm{BaTiO}_{3}$ composites with similarly sized $\mathrm{BaTiO}_{3}$ particles. When surface-modified BT3 was used, the permittivity value showed very little frequency dependency, at values close to 100 in the entire range of frequencies tested. 
Fig. 8 Storage modulus and $\tan \delta$ of compression-molded composites made with unmodified $\mathrm{BaTiO}_{3}$ and $\mathrm{BaTiO}_{3}$ modified with $1 \%$ silane

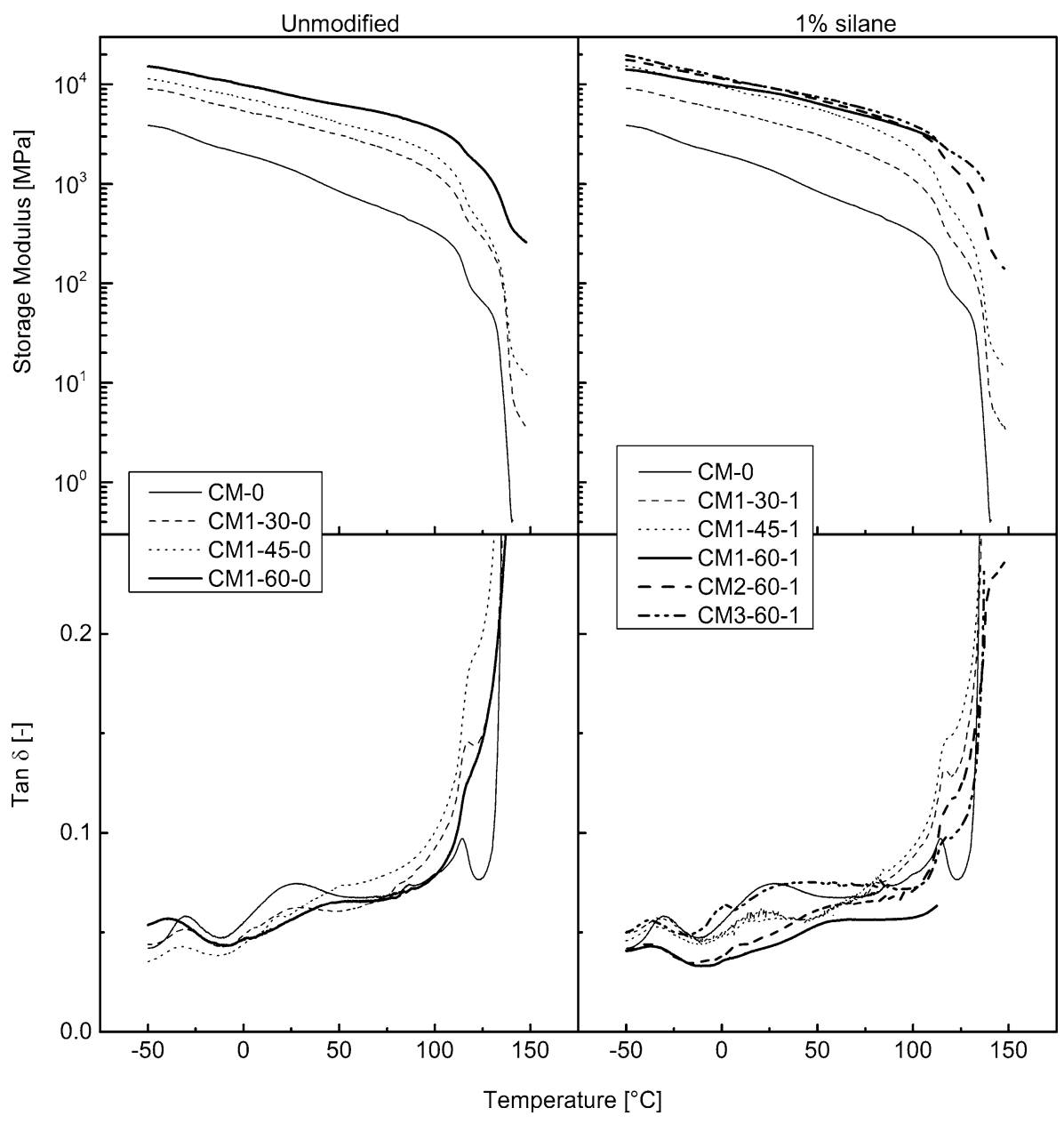

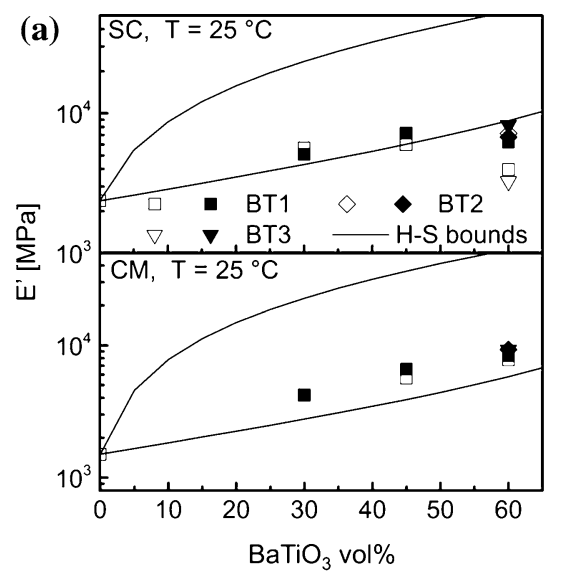

Fig. 9 a Storage modulus at $25{ }^{\circ} \mathrm{C}$ of solvent cast and compressionmolded composites made with unmodified $\mathrm{BaTiO}_{3}$ (empty symbols) and $\mathrm{BaTiO}_{3}$ modified with $1 \%$ silane (filled symbols), and HashinShtrikman (H-S) upper and lower bounds; b Storage modulus at

With the exception of the composites made with untreated BT3 powder, the $\tan \delta_{\text {diel }}$ was lower than 0.2 in the entire frequency range explored for all the solvent cast

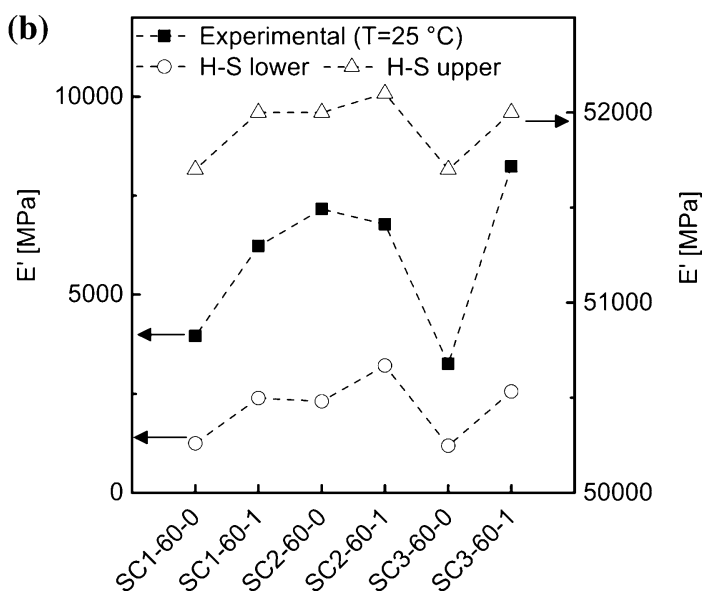

$25{ }^{\circ} \mathrm{C}$ of solvent cast materials with $60 \mathrm{vol} \% \mathrm{BaTiO}_{3}$, and the corresponding $\mathrm{H}-\mathrm{S}$ bounds calculated taking into account porosity (lines are just a guide for the eye)

and compression-molded composites containing $60 \mathrm{vol} \%$ $\mathrm{BaTiO}_{3}$. In all cases, the composites made with modified powders showed greatly reduced losses in the low 


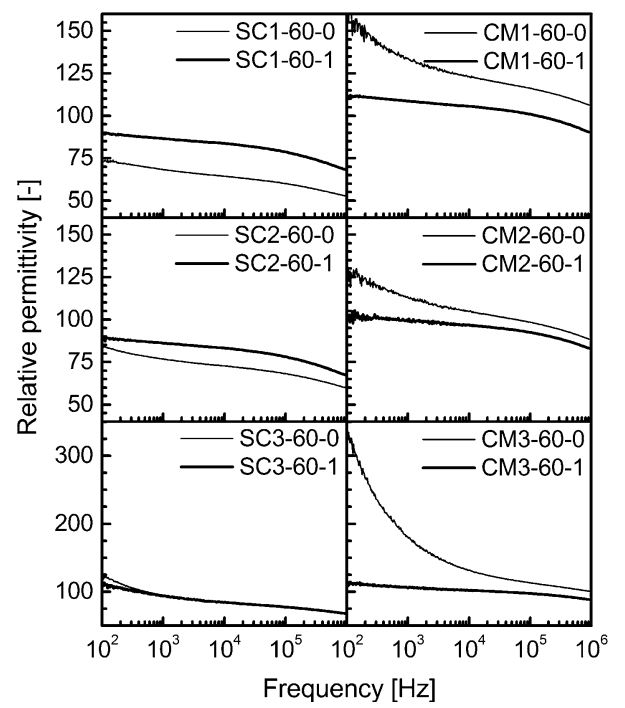

Fig. 10 Relative permittivity of solvent cast and compressionmolded composites with $60 \% \mathrm{BaTiO}_{3}$, unmodified and modified with $1 \%$ silane

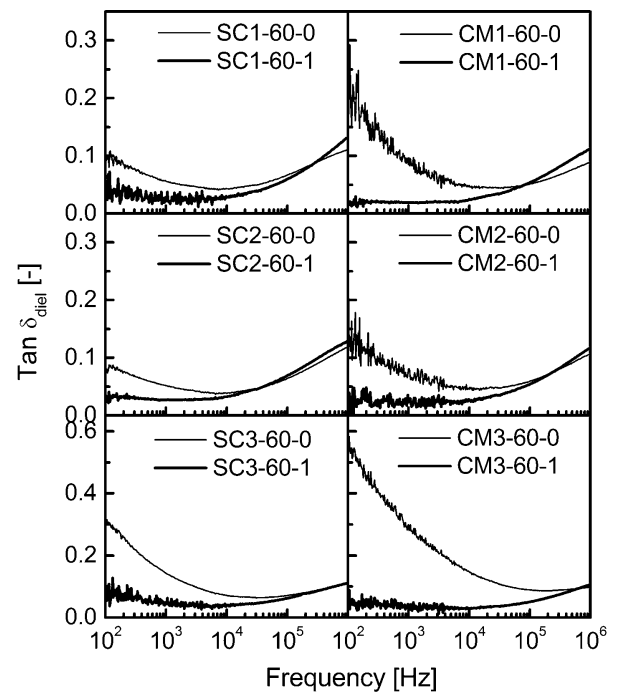

Fig. 11 Dielectric loss tangents of solvent cast and compressionmolded composites with $60 \% \mathrm{BaTiO}_{3}$, unmodified and modified with $1 \%$ silane

frequency range $\left(\tan \delta_{\text {diel }} \leq 0.05\right.$ below $\left.5 \times 10^{4} \mathrm{~Hz}\right)$ with respect to their homologues made with untreated powders.

\section{Discussion}

$\mathrm{BaTiO}_{3}$ is known to have a very high surface energy [52], at least one order of magnitude higher than MEK and P(VDF$\mathrm{TrFE})$. Therefore, during the fabrication process of the $\mathrm{P}(\mathrm{VDF}-$ $\mathrm{TrFE} / \mathrm{BaTiO}_{3}$ composites the pristine $\mathrm{BaTiO}_{3}$ particles have a high tendency to agglomeration. The surface modification with APTES, lowering the surface energy of the $\mathrm{BaTiO}_{3}$ reduces the occurrence of large aggregates and promotes a better dispersion of the particles in the composite materials. The better compatibility between the polymer and the modified particles also led to a reduction of the porosity of the solvent cast composites with high ceramic volume fractions. The enhanced matrixfiller adhesion observed by SEM for the composites made with surface-modified particles may be explained by the formation of hydrogen bonds between the $\mathrm{F}$ atoms on the polymer chain and the $\mathrm{H}$ atoms of the amino group of the silane [25]. On the other hand, the crystalline structure of the $\mathrm{BaTiO}_{3}$ particles in the composites, examined by XRD, did not show differences due to the surface modification, and the dynamic scanning calorimetry results suggest that the crystalline structure, and the degree of crystallinity of the polymer matrix were more influenced by the small fluctuations in the processing conditions than by the surface properties of the $\mathrm{BaTiO}_{3}$ particles. Therefore, the increase of the storage modulus and the decrease of $\tan \delta$ for the SC composites containing $60 \mathrm{vol} \% \mathrm{BT} 1$ and BT3 upon surface modification may be attributed mostly to decreased porosity and better dispersion of the particles. On the other hand, for SC composites containing BT2, as the dispersion state and porosity were not substantially improved by surface modification, the viscoelastic properties were not significantly affected.

The effect of surface modification on the dielectric properties was complex and can only partially be explained on the basis of the available data. The high permittivity and $\tan \delta_{\text {diel }}$ at low frequencies showed by the composites made with untreated particles may be attributed to Maxell-WagnerSillars (MWS) polarization at the polymer-ceramic interface as discussed also by Dang et al. [51] for PVDF/ $/ \mathrm{BaTiO}_{3}$ nanocomposites. For the composites made with silane-treated particles the frequency dependency of the permittivity below $10^{5} \mathrm{~Hz}$ is suppressed, indicating that the presence of the silane layer around the ceramic particles modifies the charge distribution at the interface decreasing the MWS effects.

Lower porosity resulting from $\mathrm{BaTiO}_{3}$ surface modification contributes to increasing the permittivity and reducing the dielectric losses. This is an evident effect for the solvent cast composites containing BT1. However, other factors, which may act in the same or opposite direction, must concur to the resulting permittivity. In fact, for the BT3 solvent cast composites, although a lower porosity would be inferred from the SEM observations, the density measurements and the increase in storage modulus upon modification of the powder, no significant difference in permittivity could be detected above $1 \mathrm{kHz}$. Moreover, for the compressionmolded composites, for which no differences in morphology or mechanical properties could be detected with powder surface modification, the permittivity was found to decrease, while the $\tan \delta_{\text {diel }}$ still became lower when surface-modified 
powders were used. Beier et al. [53] found that the dielectric constant of $\mathrm{BaTiO}_{3}$ particles was lower when they were modified with $n$-hexylphosphonic acid. A similar effect might give a negative contribution to the resulting permittivity of the composites upon modification of $\mathrm{BaTiO}_{3}$ with APTES. On the other hand, for the composites containing BT2 no substantial differences in porosity or aggregation could be observed by SEM or based on the mechanical properties, yet the permittivity increased and the losses decreased, when surface-modified particles were used. The reason for this behavior is unclear.

Although several questions still remain open, a potential for the improvement of both the mechanical and dielectric properties through surface modification of the ceramic particles clearly appeared from these results, particularly in the case of solvent cast composites, and further work is underway to assess the effect on the piezoelectric response.

\section{Conclusions}

Three $\mathrm{BaTiO}_{3}$ powders, two micron sized and one submicron sized, were surface modified with (3-aminopropyl) triethoxy silane, and solvent cast and compression-molded composites with volume fractions of unmodified and modified ceramic up to $60 \%$ were fabricated and characterized.

Particle surface modification was found to be effective for improving the dispersion of the ceramic in the matrix, reducing the particle aggregates and promoting the compatibility and adhesion of the $\mathrm{P}(\mathrm{VDF}-\mathrm{TrFE})$ matrix to the filler, while not affecting the crystalline structure of the ceramic particles and the crystallinity of the polymer matrix. The effect of the surface modification of $\mathrm{BaTiO}_{3}$ was more pronounced for the solvent cast composites. The storage modulus and relative permittivity of the composites containing $60 \mathrm{vol} \% \mathrm{BaTiO}_{3}$ were higher or similar, while both the viscoelastic and dielectric losses were lower, when surface-modified particles were used. For the compressionmolded composites, the viscoelastic properties were not substantially affected, while both the permittivity and the dielectric losses slightly decreased upon surface modification of the ceramic particles. For all composites, the marked frequency dependency of relative permittivity below $10^{4} \mathrm{~Hz}$ was suppressed by surface modification of the ceramics, obtaining a relatively constant value of in the $10^{2}-10^{5} \mathrm{~Hz}$ range.

Acknowledgements The authors would like to thank the Swiss National Science Foundation for funding in the framework of the Marie Heim-Vögtlin and Nano-Tera programs, and Solvay Solexis SpA for kindly providing the $\mathrm{P}(\mathrm{VDF}-\mathrm{TrFE})$ and for fruitful discussion. Dr Li Jin, Felix Lindström and Arthur Aebersold are acknowledged for technical support, and the Powder Technology Laboratory
(EPFL) and the Interdisciplinary Centre for Electron Microscopy (EPFL) for use of their equipment.

\section{References}

1. Lovinger AJ (1983) Ferroelectric polymers. Science 220: 1115-1121

2. Dang Z-M, Yuan J-K, Zha J-W, Zhou T, Li S-T, Hu G-H (2012) Fundamentals, processes and applications of high-permittivity polymer-matrix composites. Prog Mater Sci 57:660-723

3. Barber P, Balasubramanian S, Anguchamy Y et al (2009) Polymer composite and nanocomposite dielectric materials for pulse power energy storage. Materials 2:1697-1733

4. Wang Q, Zhu L (2011) Polymer nanocomposites for electrical energy storage. J Polym Sci, Part B 49:1421-1429

5. Thakur VK, Tan EJ, Lin MF, Lee PS (2011) Poly(vinylidene fluoride)-graft-poly(2-hydroxyethyl methacrylate): a novel material for high energy density capacitors. J Mater Chem 21:3751-3759

6. Thakur VK, Tan EJ, Lin MF, Lee PS (2011) Polystyrene grafted polyvinylidenefluoride copolymers with high capacitive performance. Polym Chem 2:2000-2009

7. Thakur VK, Lin MF, Tan EJ, Lee PS (2012) Green aqueous modification of fluoropolymers for energy storage applications. J Mater Chem 22:5951-5959

8. Chan HLW, Cheung MC, Choy CL (1999) Study on $\mathrm{BaTiO}_{3} /$ P(VDF-TrFE) 0-3 composites. Ferroelectrics 224:541-548

9. Hsiang HI, Lin KY, Yen FS, Hwang CY (2001) Effects of particle size of $\mathrm{BaTiO}_{3}$ powder on the dielectric properties of $\mathrm{BaTiO}_{3} /$ polyvinylidene fluoride composites. J Mater Sci 36:3809-3815. doi:10.1023/A:1017946405447

10. Chanmal CV, Jog JP (2008) Dielectric relaxations in PVDF/Ba$\mathrm{TiO}_{3}$ nanocomposites. Express Polym Lett 2:294-301

11. Cheung MC, Chan HLW, Choy CL (2001) Dielectric relaxation in barium titanate/polyvinylidene fluoride-trifluoroethylene composites. Ferroelectrics 264:1721-1726

12. Gregorio R, Cestari M, Bernardino FE (1996) Dielectric behaviour of thin films of beta-PVDF/PZT and beta-PVDF/BaTiO composites. J Mater Sci 31:2925-2930. doi:10.1007/BF00356003

13. Lin MF, Thakur VK, Tan EJ, Lee PS (2011) Dopant induced hollow $\mathrm{BaTiO}_{3}$ nanostructures for application in high performance capacitors. J Mater Chem 21:16500-16504

14. Wang QT, Jiang WL, Guan SW, Zhang YH (2013) Preparation and dielectric properties of AGS@CuPc/PVDF composites. J Inorg Organomet Polym Mater 23:743-750

15. Kuang XW, Liu Z, Zhu H (2013) Dielectric properties of Ag@C/ PVDF composites. J Appl Polym Sci 129:3411-3416

16. Chiolerio A, Lombardi M, Guerriero A et al (2013) Effect of the fabrication method on the functional properties of $\mathrm{BaTiO}_{3}$ : PVDF nanocomposites. J Mater Sci 48:6943-6951. doi:10.1007/s10853-0137500-9

17. Dalle Vacche S, Oliveira F, Leterrier Y, Michaud V, Damjanovic D, Månson JAE (2012) The effect of processing conditions on the morphology, thermomechanical, dielectric, and piezoelectric properties of $\mathrm{P}(\mathrm{VDF}-\mathrm{TrFE}) / \mathrm{BaTiO}_{3}$ composites. J Mater Sci 47:4763-4774. doi:10.1007/s10853-012-6362-x

18. Marra SP, Ramesh KT, Douglas AS (1999) The mechanical properties of lead-titanate/polymer 0-3 composites. Compos Sci Technol 59:2163-2173

19. Marra SP, Ramesh KT, Douglas AS (1999) The mechanical and electromechanical properties of calcium-modified lead titanate/ poly(vinylidene fluoride-trifluoroethylene) 0-3 composites. Smart Mater Struct 8:57-63

20. Mendes SF, Costa CM, Caparros C, Sencadas V, LancerosMéndez S (2012) Effect of filler size and concentration on the 
structure and properties of poly(vinylidene fluoride)/ $/ \mathrm{BaTiO}_{3}$ nanocomposites. J Mater Sci 47:1378-1388. doi:10.1007/s10853011-5916-7

21. Lonjon A, Demont P, Dantras E, Lacabanne C (2012) Mechanical improvement of $\mathrm{P}(\mathrm{VDF}-\mathrm{TrFE}) /$ nickel nanowires conductive nanocomposites: influence of particles aspect ratio. J Non-Cryst Solids 358:236-240

22. El Achaby M, Essassi EM, el KacemQaiss A (2013) Melt processing of polyvinylidene fluoride based composites containing mineral nanoparticles. Key Eng Mater 550:165-170

23. Osinska K, Czekaj D (2013) Thermal behavior of BST//PVDF ceramic-polymer composites. J Therm Anal Calorim 113:69-76

24. Muralidhar C, Pillai PKC (1989) Matrix filler interactions and its influence on barium-titanate $\left(\mathrm{BaTiO}_{3}\right) /$ polyvinylidene fluoride (PVDF) composite. Ferroelectrics 89:17-26

25. Dang ZM, Wang HY, Xu HP (2006) Influence of silane coupling agent on morphology and dielectric property in $\mathrm{BaTiO}_{3} /$ polyvinylidene fluoride composites. Appl Phys Lett 89:112902

26. Kelarakis A, Hayrapetyan S, Ansari S, Fang J, Estevez L, Giannelis EP (2010) Clay nanocomposites based on poly(vinylidene fluoride-co-hexafluoropropylene): structure and properties. Polymer 51:469-474

27. Song R, Yang D, He L (2007) Effect of surface modification of nanosilica on crystallization, thermal and mechanical properties of poly(vinylidene fluoride). J Mater Sci 42:8408-8417. doi:10. 1007/s10853-007-1787-3

28. Livi S, Duchet-Rumeau J, Gerard JF (2011) Tailoring of interfacial properties by ionic liquids in a fluorinated matrix based nanocomposites. Eur Polym J 47:1361-1369

29. Thakur VK, Yan J, Lin MF, Zhi CY et al (2012) Novel polymer nanocomposites from bioinspired green aqueous functionalization of BNNTs. Polym Chem 3:962-969

30. Morel F, Bounor-Legare V, Espuche E, Persyn O, Lacroix M (2012) Surface modification of calcium carbonate nanofillers by fluoro- and alkyl-alkoxysilane: consequences on the morphology, thermal stability and gas barrier properties of polyvinylidene fluoride nanocomposites. Eur Polym J 48:919-929

31. Nguyen VS, Rouxel D, Vincent B et al (2013) Influence of cluster size and surface functionalization of $\mathrm{ZnO}$ nanoparticles on the morphology, thermomechanical and piezoelectric properties of P(VDF-TrFE) nanocomposite films. Appl Surf Sci 279:204-211

32. Kim P, Doss NM, Tillotson JP et al (2009) High energy density nanocomposites based on surface-modified $\mathrm{BaTiO}_{3}$ and a ferroelectric polymer. ACS Nano 3:2581-2592

33. Lin MF, Thakur VK, Tan EJ, Lee PS (2011) Surface functionalization of $\mathrm{BaTiO}_{3}$ nanoparticles and improved electrical properties of $\mathrm{BaTiO}_{3} /$ polyvinylidene fluoride composite. RSC Adv 1:576-578

34. Yu K, Wang H, Zhou YC, Bai YY, Niu YJ (2013) Enhanced dielectric properties of $\mathrm{BaTiO}_{3} /$ poly(vinylidene fluoride) nanocomposites for energy storage applications. J Appl Phys 113: 034105

35. Dou XL, Liu XL, Zhang Y, Feng H, Chen JF, Du S (2009) Improved dielectric strength of barium titanate-polyvinylidene fluoride nanocomposite. Appl Phys Lett 95:132904

36. Zhou T, Zha JW, Cui RY, Fan BH, Yuan JK, Dang ZM (2011) Improving dielectric properties of $\mathrm{BaTiO}_{3} /$ ferroelectric polymer composites by employing surface hydroxylated $\mathrm{BaTiO}_{3}$ nanoparticles. ACS Appl Mater \& Interfaces 3:2184-2188

37. Almadhoun MN, Bhansali US, Alshareef HN (2012) Nanocomposites of ferroelectric polymers with surface-hydroxylated $\mathrm{BaTiO}_{3}$ nanoparticles for energy storage applications. J Mater Chem 22:11196-11200

38. Lin MF, Lee PS (2013) Formation of PVDF-g-HEMA/BaTiO nanocomposites via in situ nanoparticle synthesis for high performance capacitor applications. J Mater Chem A 1:14455-14459

39. Simoes R, Rodriguez-Perez M, De Saja J, Constantino C (2009) Tailoring the structural properties of PVDF and P(VDF-TrFE) by using natural polymers as additives. Polym Eng Sci 49: $2150-2157$

40. Tanaka H, Yukawa H, Nishi T (1988) Effect of crystallization condition on the ferroelectric phase-transition in vinylidene fluoride trifluoroethylene (VF2/F3E) copolymers. Macromol 21:2469-2474

41. Hashin Z, Shtrikman S (1963) A variational approach to the theory of the elastic behaviour of multiphase materials. J Mech Phys Solids 11:127-140

42. Gibson L, Ashby MF (1988) Cellular solids-structure and properties. Pergamon Press, Oxford

43. Frübing P, Wang FP, Gunter C, et al. (2010) In: Proceedings of the 2010 IEEE international conference on solid dielectrics (ICSD 2010), University of Potsdam, Potsdam, Germany

44. Linares A, Acosta JL (1997) Tensile and dynamic mechanical behaviour of polymer blends based on PVDF. Eur Polym J 33:467-473

45. Sencadas V, Lanceros-Mendez S, Mano JF (2004) Characterization of poled and non-poled beta-PVDF films using thermal analysis techniques. Thermochim Acta 424:201-207

46. Zhang SH, Klein RJ, Ren KL et al (2006) Normal ferroelectric to ferroelectric relaxor conversion in fluorinated polymers and the relaxor dynamics. J Mater Sci 41:271-280. doi:10.1007/s10853006-6081-2

47. Omote K, Ohigashi H, Koga K (1997) Temperature dependence of elastic, dielectric, and piezoelectric properties of "single crystalline" films of vinylidene fluoride trifluoroethylene copolymer. J Appl Phys 81:2760-2769

48. Parry EJ, Tabor D (1973) Effect of hydrostatic pressure and temperature on mechanical loss properties of polymers. 2. Halogen polymers. Polymer 14:623-627

49. Yagi T, Tatemoto M, Sako J (1980) Transition behavior and dielectric-properties in trifluoroethylene and vinylidene fluoride co-polymers. Polym J 12:209-223

50. Sencadas V, Lanceros-Méndez S, Mano JF (2006) Thermal characterization of a vinylidene fluoride-trifluorethylene (75-25) (\%mol) copolymer film. J Non-Cryst Solids 352:5376-5381

51. Dang ZM, Xu HP, Wang HY (2007) Significantly enhanced lowfrequency dielectric permittivity in the $\mathrm{BaTiO}_{3} /$ poly(vinylidene fluoride) nanocomposite. Appl Phys Lett 90:012901

52. Cohen RE (2007) Theory of ferroelectrics: a vision for the next decade and beyond. In: Gonzalo JA, Jiménez B (eds) Ferroelectricity. Wiley-VCH, Weinheim, pp 139-154

53. Beier CW, Cuevas MA, Brutchey RL (2010) Effect of surface modification on the dielectric properties of $\mathrm{BaTiO}_{3}$ nanocrystals. Langmuir 26:5067-5071 